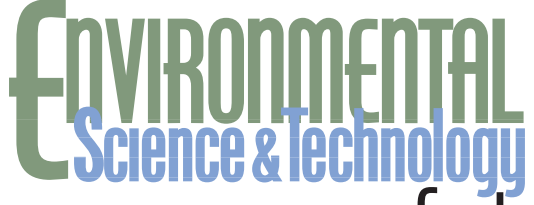

\section{Delivering Sustainable Infrastructure that Supports the Urban Built Environment}

\author{
CAROL BOYLE* \\ The University of Auckland, New Zealand \\ G A V I N M U D D \\ Monash University, Clayton, Victoria, Australia
}

J A M E S R. M I H E L C I C

University of South Florida, Tampa

PAUL ANASTAS

Yale University, New Haven, Connecticut

T E R R Y C O L L I N S

Carnegie Mellon University, Pittsburgh, Pennsylvania

P A T R I C I A C U LL I G A N

Columbia University, New York

MARC EDWARDS

Virginia Polytechnic Institute and State University, Blacksburg, Virginia

J ER E M Y GAB E

Landcare Research, Auckland, New Zealand

PATRICIA GALLA GHER

Drexel University, Philadelphia, Pennsylvania

S U S A N HANDY

University of California Davis, California

J E H N G - J U N G KA O

National Chiao Tung University, Hsinchu City, Republic of China

S U S A N KR U M D I E C K

University of Canterbury, Christchurch, New Zealand

LIONEL D. LYLES

Southern University, Baton Rouge, Louisiana

I A N M A S O N

University of Canterbury, Christchurch, New Zealand

R O N M C D O W A L L

The University of Auckland, New Zealand

4836 - ENVIRONMENTAL SCIENCE \& TECHNOLOGY / VOL. 44, NO. 13, 2010
ANN IE PEARCE

Virginia Polytechnic Institute and State University, Blacksburg, Virginia

CHRIS RIEDY

University of Technology, Sydney, Australia

J O H N R U S S E L L

La Trobe University, Melbourne, Australia

JER A L D L. S C H N O O R

University of Iowa, Iowa City

MAYA TROTZ

University of South Florida, Tampa

R O GER VENAB LE S

Crane Environmental Ltd, Surrey, U.K.

J U L I E B . Z I M M E R M A N

Yale University, New Haven, Connecticut

VALERIE F UCHS

Michigan Technological University, Houghton

S A R A H M I L E R

Yale University, New Haven, Connecticut

S H A N N O N PAGE

University of Canterbury, Christchurch, New Zealand

KAREN REEDER-EMERY

Southern University, Baton Rouge, Louisiana

Sustainable living will require megacity-level infrastructural support designs and paradigms.

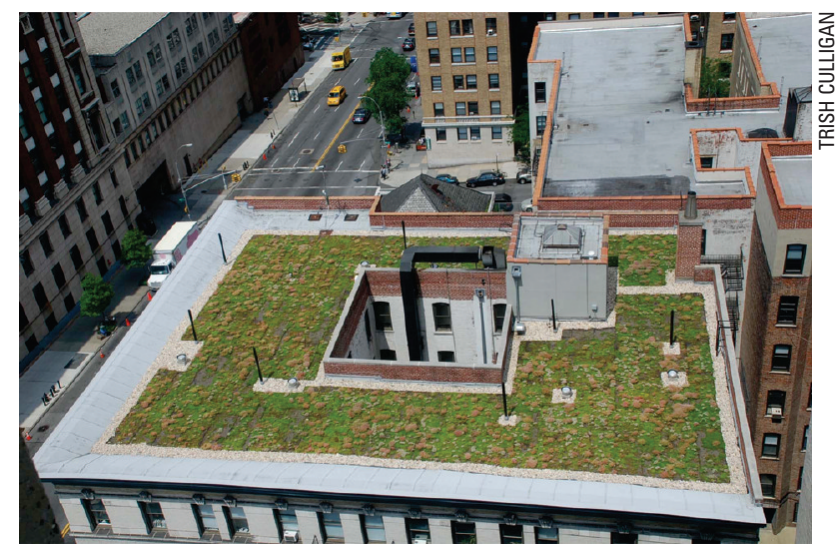

10.1021/es903749d (c) 2010 American Chemical Society Published on Web 06/29/2010 
Over $50 \%$ of the global population now lives in urban areas (1). Over the past century, urban areas have expanded at a greater rate than population growth, increasing requirements for resources and producing greater impacts on the natural environment. Urban societies have also changed, with a greater diversity of cultures, high population densities, and rising demand for services, resulting in an increasing complexity of human urban systems. Urban systems influence and are influenced by infrastructure systems, which affect the design and management of the built, social, and natural environments, including future infrastructure decisions.

Sustainable infrastructure that supports the built environment is essential for the survival and health and wellbeing of a society. The built environment includes buildings, engineering works, and infrastructure such as roads, wastewater and water treatment plants, stormwater management systems, power generation facilities, railways, bridges, and even natural systems such as rivers and harbors. Infrastructure systems provide the basic physical structures needed for the operation of a society and facilitate access to goods and services.

There is already significant awareness of and action focused on urban sustainability. Green building standards have promoted life cycle thinking in design and manufacture of materials and products and have raised community-level awareness of infrastructure considerations and operational characteristics associated with buildings. Low impact design (LID) of infrastructure, which reduces environmental impact, is now being incorporated into urban developments. Life cycle and impact assessments of materials and infrastructure systems together with material flow and urban metabolism studies are improving understanding of resource use and informing needs for future infrastructure design, construction, and management $(2-6)$. Yet it is not clear if these approaches will deliver sustainable infrastructure (7).

There is an increasing awareness that cities function as complex, dynamic urban ecosystems (8) and that infrastructure is critical in delivering sustainable cities. Thus major shifts in planning, decision making and implementation will be needed to address the challenge of urban sustainability. Developing sustainable infrastructure systems will require a greater understanding of their complexity and dynamics, using an interdisciplinary approach. This paper presents the results of a multidisciplinary, international workshop that identified

- challenges in developing and managing sustainable infrastructure which need to be addressed by research

- priorities for research into the urban built environment that are necessary to achieve sustainable infrastructure.

\section{Workshop}

The workshop was attended by 28 researchers from the U.S., U.K., Australia, Taiwan, and New Zealand, with expertise in green buildings, geotechnical engineering, water management, construction, sustainable design, urban design and infrastructure, energy, climate change, transportation, developing countries, mining, public policy, and chemistry. Presentations on urban infrastructure challenges were followed by a discussion on the research issues that were seen as priority. Key research themes were then identified and developed in greater detail.

Urban Infrastructure Challenges. Challenges in developing a framework to deliver sustainable infrastructure include the following:

Improving Understanding of Sustainability. While the term "sustainability" has been used for many purposes, the science underpinning it is unclear. The Brundtland (9) definition of "Ensuring the needs of the current generation are met without compromising the needs of future generations", despite its many interpretations, is still fundamental. Overall, however, there is agreement that inter- and intragenerational equity and the sustainability of environment and society are important. Most researchers agree that an ecosystems thinking approach, recognizing the complex, multiscale, dynamic nature of human and ecological systems, is essential for achieving sustainability $(8,10-14)$.

The role of resilience in complex system function and in achieving sustainable systems has been widely debated $(11,12,14-16)$. However, there is still contention with respect to measuring resilience, effective ways of increasing resilience in systems, and whether resilience alone can deliver sustainable human systems (10). Even the factors which make a system resilient have yet to be identified (17). Research is now focusing on better understanding complex, sociotechnical systems, such as urban infrastructure, and their sustainability.

Global Warming. Global warming models predict possible changes in temperature, precipitation patterns, storm surges, increases in sudden, catastrophic weather events, and in sea levels $(18,19)$. The ramifications for infrastructure are significant and will affect planning, designing, operating, maintaining, and upgrading of infrastructure. Many cities, such as London, are constructing greater flood protection to meet model predictions. The impact of Hurricane Katrina on New Orleans is a timely warning of a city inherently vulnerable to extreme weather events.

Increased Urbanization. Most of the 3 billion people projected to be added to the global population over the next 50 years will reside in cities (20). The number of megacities (population $>10$ million) has increased from 3 in 1975 to 19 in 2007; by 2025, this number is expected to rise to 27 , with 6 cities projected to have populations over 20 million (20). There is limited understanding of the complexity and risks of the large-scale infrastructure systems being developed to serve megacities. However, the criticality of providing sufficient resources so as to prevent social unrest and conflict makes sustainable megacity infrastructures especially vital.

Increasing Age and Risk of Failure in Urban Infrastructure. Many of the major cities in Europe and North America have road, sewer, and water infrastructure systems that combine century old infrastructure with upgraded or new construction and technology. Such systems may fail as the capability and resources to maintain them vanishes. The American Society of Civil Engineering's 2009 Infrastructure Report rates U.S. infrastructure systems with an overall grade of D; solid waste ranked highest at $\mathrm{C}+$, and water, wastewater, roads, levees, and waterways all received $\mathrm{D}-(21)$. The estimated financial investment required for infrastructure upgrading for the U.S. is $\$ 2.2$ trillion over five years.

Increase in Consumption in Developing Countries. While the per capita consumption of developing countries remains below that of the developed world, population, consumption, and subsequent economic growth in China and India are increasing rapidly. These increases are driving consumption of natural resources both locally and internationally, causing escalating impacts on environments and societies across the globe.

Resource Availability: Energy, Water, and Construction Materials. Peak oil (the point of maximum global oil production), declining oil supplies (22), and increasing severe water scarcity (annual water supplies below $1000 \mathrm{~m}^{3} /$ person) (1) will have major impacts on the production and supply of food, water, electricity, transportation, communication, and most consumer goods. There are also significant concerns about the growing environmental footprint of mining $(23,24)$; increasing demands for metals and other materials will only add to those concerns. 
The volume of materials and energy that flows through urban systems is significant and rising because of rising consumption and population $(25,26)$. In 2000, London's ecological footprint was twice the land mass of the U.K., consuming $3.76 \mathrm{t}$ construction materials per capita and producing 2.03 t construction and demolition waste per capita (27). Energy consumption and $\mathrm{CO}_{2}$ production from vehicle travel has risen because of urban sprawl despite more efficient technology (28): materials are now transported significant distances into cities as local sources are exhausted or overtaken by urbanization, increasing energy consumption, emissions of $\mathrm{CO}_{2}, \mathrm{NO}_{\mathrm{x}}$, and volatile organic carbons (VOCs), and, consequently, respiratory illnesses (28).

Sustainability is a global challenge but many of the solutions must be implemented at the local level. Research is needed to

- establish the fundamentals of the science of sustainability as a foundation for infrastructure

- enable a greater understanding of the risks inherent in the large, multiple-scale, complex, dynamic systems which comprise infrastructure systems

- assist in developing better responses to climate change, increased urbanization, increasing use of limited resources, and aging urban infrastructure

\section{Directions and Research Themes}

Two main research themes were identified: (a) to better understand sustainable systems and (b) to develop sustainable infrastructure systems; for each, key research directions were further developed. While the focus was on sustainability, systems thinking, complexity, and resilience were found to be fundamental elements. A few directions were aimed at short-term requirements, such as assessment of the sustainability of mixed scale infrastructure systems (e.g., provision of water through a combination of small-scale rain tanks, medium-scale community underground storage tanks, and large-scale reservoirs). Medium term needs were also considered, including development of infrastructure to address global warming concerns by 2020, while other directions focused on long-term aspects, including the development of sustainable infrastructure for megacities by 2100 . Incorporating the social context of sustainability in developing sustainable infrastructure was widely vital.

Overall it was recognized that there is a need to better understand the components of a sustainable system and how to incorporate such into infrastructure development, either on a transitionary path or ultimately. There was also discussion regarding the validity of incremental improvements in achieving sustainability; a number of researchers postulated that only path-breaking designs could achieve such a goal.

Fundamentals of Sustainable Infrastructure Systems. Understanding the dynamics and function of complex human systems and the human/environment interaction was deemed essential in understanding sustainability and how a sustainable system could be achieved. The four key directions for this theme were aimed at identifying and understanding:

- the dynamics and function of societal systems

- the nature and dynamics of sustainable systems

- the roles, limits, and interrelations among environmental, social, technological, institutional, and economic systems

- the nature of increasing complexity in human systems

Dynamics and Function of Human Systems. Feedback mechanisms, system fluctuations over space and time, synergistic, antagonistic, and cumulative interactions, as well as complex system failure modes, are examples of poorly understood aspects of societal systems. Understanding of the function of the community in delivering sustainability, particularly in reducing infrastructure burdens through changes in human behavior and consumption patterns, is also essential. The influence of infrastructure systems on urban development, function, management, and growth over short, medium, and long term also needs exploration, particularly the implications of new technologies such as desalinization and low impact design (LID).

It was suggested that risk assessment has the potential to be used to gauge the sustainability of a system. However, there is little understanding of the risk in complex systems, particularly dealing with interdependencies, feedback mechanisms, and emergent properties inherent to complex systems.

Nature and Dynamics of Sustainable Systems. Much current infrastructure is centralized, and it is unclear if this is a sustainable model for development and management. Lowimpact, decentralized, or mixed decentralized-centralized infrastructure systems need to be assessed against existing systems to identify potential risks and resilience and identify appropriate options for development or redevelopment. The degree of decentralization may be different for energy, water, and wastewater infrastructures and will be influenced by local factors such as geography, hydrology, existing infrastructure, and consumer demands. Overall, features of sustainable systems are still under debate, and a greater understanding of the factors that contribute to sustainability is needed.

Roles, Limits, and Interrelations Among Environmental, Social, Technological, Institutional, and Economic Systems. Interrelationships within human society and between that and the environment influence societal sustainability but with poorly understood interrelationships. There is also little knowledge as to the limits of environmental and social systems, particularly with respect to resource availability, environmental system function, and social needs and limits for sustaining human systems. Climate change research provides a good example of how interrelationships between society, technology, management, governance, economics, and the environment need to be considered and parsed: a particular example being the limits for $\mathrm{CO}_{2 \mathrm{e}}$ proposed by climate scientists to prevent excessive global warming.

The focus on economics to the detriment of society and the environment has been criticized as a barrier to sustainability and to engaging society in a meaningful dialogue for sustainable lifestyles and communities. There are also concerns that too much emphasis has been placed on technology with little consideration of appropriate technology and the resource and economic costs to future generations to maintain and upgrade infrastructure.

Increasing Complexity in Human Societies. Increasing population, consumption, density, diversity, globalization, and communication and current trends indicate increasing human societal complexity. As new technologies and potential solutions to current issues are developed, there will be both positive and negative repercussions from their implementation. Pathways for delivering sustainable infrastructure will need to be carefully developed.

Meeting the needs of both megacities and megabuildings (which we have defined as mixed-use buildings over $300 \mathrm{~m}$ in height) will require development and management of increasingly complex infrastructure systems that exceed existing capabilities. The risks of such mega-systems are not yet well understood, and it is expected that there will be emergent properties. The functioning of megabuildings, or "vertical urban villages", may pose significant new challenges and require novel solutions because of the scaling issues. 


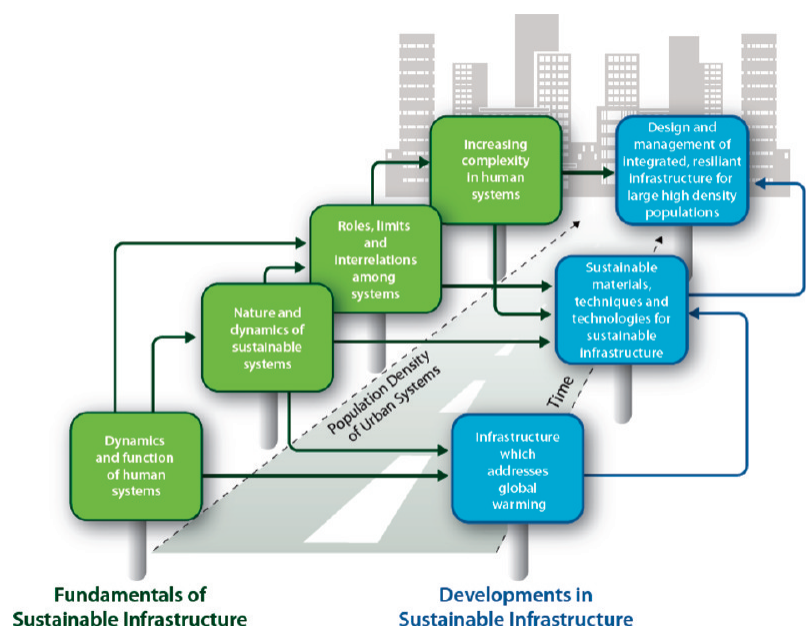

FIGURE 1. Research directions required to achieve sustainable infrastructure for the built environment.

\section{Developments in Sustainable Infrastructure}

While research into fundamentals is essential, frameworks for developing technologies, materials, and approaches need to be considered. Key research directions include

- developing infrastructure that addresses global warming, in both reducing global warming and addressing changing climatic conditions

- developing sustainable materials, techniques, and technologies for construction of sustainable infrastructure

- designing and managing integrated, resilient, infrastructure for large, high density populations

Developing Infrastructure that Addresses Global Warming by Both Reducing Global Warming and Addressing Changing Climatic Conditions. Absorption of greenhouse gases (GHGs), either during production of new building materials or use of new infrastructure/building technologies, such as green walls and green roofs, would assist in reducing the atmospheric burden. It is even hypothesized that changing the albedo of buildings and surfaces will reduce localized warming. New materials and technologies need to be implemented without causing feedback problems (e.g., using carbon storage to mitigate, and thus encourage, the use of coal rather than further reducing atmospheric carbon). Future infrastructure designs will also have to take account of local climatic and sea level changes. Since the contributions to and expected changes from global warming are location dependent, research is required to deliver capable local infrastructure systems.

Developing Sustainable Materials, Techniques, and Technologies for Construction and Management of Sustainable Infrastructure. New materials, designs, construction methods, and techniques for buildings and infrastructure to reduce resource consumption, environmental impact, and waste production need to be developed and assessed over their life cycle to ensure their sustainability. These also need to be utilized appropriately, instead of being regarded as the solution simply because they are new. While incremental changes in current materials, technologies, and systems may be acceptable for the short-term, it will be necessary to develop path-breaking directions if sustainability is to be achieved. Such changes will probably need decadal, if not longer durations, and require innovative thinking and vision to develop.

Designing and Managing Sustainable, Integrated, Resilient Infrastructure for Large, High-Density Populations. There are two foci for this research into sustainable design: (a) developing and upgrading "mixed" infrastructure systems and (b) designing and constructing infrastructure for new a)

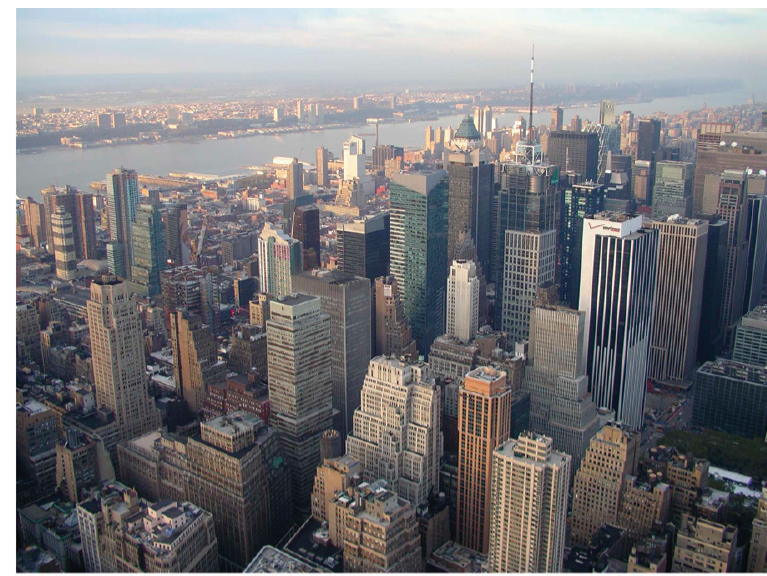

b)

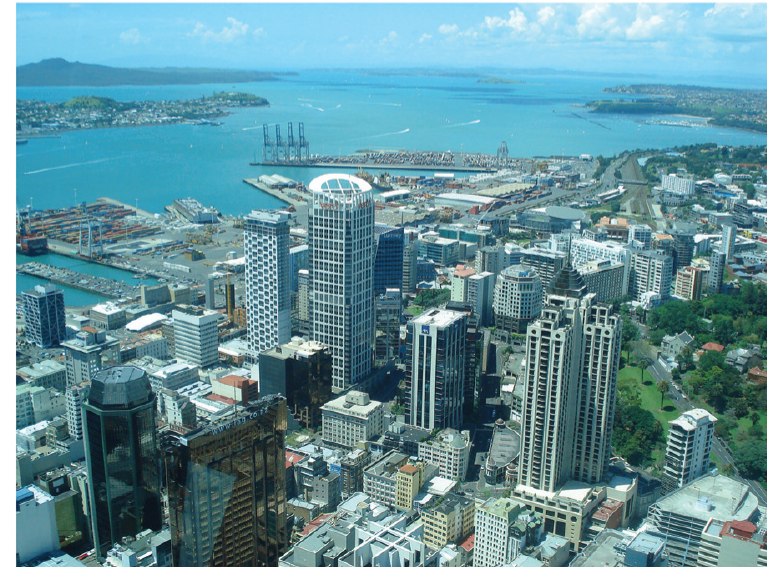

FIGURE 2. Higher density and population, combined with an aging, unsustainable infrastructure, will mean that New York City (a) will require long-term funding, planning and engineering to transition to a sustainable infrastructure. Auckland (b), with a younger infrastructure and lower density and population, will need to consider new types of infrastructure and resource management to ensure it embeds a sustainable infrastructure as it continues to grow.

ANTHEA CLAIRE JOHNSON/AVISHAI CEDER

developments that can successfully integrate with older designs and technologies. In addition, new infrastructure systems must cope with large, dense populations with high resource needs and may rely on new technologies that leapfrog older technologies and thus require new management and construction concepts. Yet, for some systems, upgrading old technologies and incorporating passive design principles might achieve sustainability.

All of the research directions recognized that systems thinking, complexity, and resilience are fundamentals in understanding and delivering sustainability. Short-, medium-, and long-term thinking at varying scales is also needed to understand the complex social systems that drive and develop infrastructure systems and protect the environmental systems which provide many of society's resources (Figure 1). Both societal and individual needs must be incorporated into infrastructure design; an understanding of the social infrastructure and its interaction with the physical infrastructure was considered essential. Consequently, engineers need to be encouraged to work with both communities and businesses and be flexible to achieve successful outcomes.

Finally, there was consensus that new perspectives, technologies, and behaviors were needed to drive the innovations required to meet the needs of an expanding society for the future. While incremental changes were necessary, disruptive, path-breaking changes may be essential to developing sustainable infrastructure systems that may require 10-20 years before implementation. The research 
directions developed in this workshop were seen as only the beginning of a long pathway to sustainable infrastructures, cities and societies. We welcome ongoing discussions of this ilk as the all-hands task of building sustainably for our common future proceeds.

Dr. Carol Boyle is an associate professor in civil and environmental engineering at The University of Auckland, New Zealand. Dr. Gavin Mudd is a lecturer in civil engineering at Monash University, Australia. Dr. James R. Mihelcic is a professor in civil and environmental engineering, University of South Florida, Florida. Dr. Paul Anastas is professor of green chemistry at Yale University, Connecticut. Dr. Terry Collins is Thomas Lord Professor of Chemistry, Carnegie Mellon University, Pennsylvania. Dr. Patricia Culligan is a professor in civil engineering and engineering mechanics, Columbia University, New York. Dr. Marc Edwards is a professor in civil and environmental engineering, Virginia Polytechnic Institute and State University, Virginia. Jeremy Gabe is a researcher with Landcare Research, Auckland, NZ. Dr. Patricia Gallagher is an associate professor in the Department of Civil, Architectural, and Environmental Engineering, Drexel University, Pennsylvania. Dr. Susan Handy is a professor in the Department of Environmental Science and Policy and Director of the Sustainable Transportation Center, University of California Davis, California. Dr. Jehng-Jung Kao is a professor in the Institution of Environmental Engineering at National Chiao Tung University, Republic of China. Dr. Susan Krumdieck is an associate professor in the Department of Mechanical Engineering at the University of Canterbury, NZ. Dr. Lionel D. Lyles is the Director, PhD Program in Public Policy in the Nelson Mandela School of Public Policy and Urban Affairs, and Research Professor for the Southern University Center for Coastal Zone Assessment and Remote Sensing at Southern University, Louisiana. Dr. Ian Mason is a research fellow in the Department of Civil and Natural Resources Engineering and a senior fellow in the Department of Accounting and Information Systems, University of Canterbury, NZ. Dr. Ron McDowall is a senior lecturer in the Faculty of Business at The University of Auckland. NZ. Dr. Annie Pearce is the LEED Associate Professor in the Department of Building Construction at the Myers-Lawson School of Construction at Virginia Polytechnic Institute and State University, Virginia. Dr. Chris Riedy is the Research Director of the Institute of Sustainable Futures at University of Technology Sydney, Australia. Dr. John Russell is a lecturer in the Department of Civil Engineering and Physical Sciences at La Trobe University, Australia. Dr. Jerald Schnoor holds the Allen S. Henry Chair in Engineering Department of Civil and Environmental Engineering and is Co-Director of the Center for Global and Regional Environmental Research at University of Iowa, Iowa. Dr. Maya Trotz is an assistant professor and the Patel Global Solutions Fellow in the Department of Civil and Environmental Engineering at the University of South Florida, Florida. Roger Venables is the Royal Academy of Engineering Visiting Professor in Engineering Design for Sustainable Development at Queen's University, Belfast and a managing director of Crane Environmental, U.K. Dr. Julie B. Zimmerman is the Assistant Professor of Green Engineering and the Assistant Director for Research at Center for Green Chemistry and Green Engineering, Yale University, Connecticut. Valerie Fuchs was a doctoral student and research assistant at Michigan Technological University, Michigan. Sarah Miller was a doctoral student and research assistant in the Department of Environmental Engineering at Yale University, Connecticut. Shannon Page was a doctoral student and research assistant at University of Canterbury, NZ. Karen Reeder-Emery was a doctoral student and research assistant at Southern University, Louisiana. Please address all correspondence to Dr. Carol Boyle at c.boyle@auckland.ac.nz.

\section{Acknowledgments}

This material is based upon work supported by the National Science Foundation under Grant No. CMMI-0855644. Any opinions, findings, and conclusions or recommendations expressed in this material are those of the authors and do not necessarily reflect the views of the National Science Foundation. Funding was also provided by Waitakere City Council, Waitakere City, New Zealand.

\section{Literature Cited}

(1) United Nations Environment Programme Global Environmental Outlook 4. UNEP, Nairobi, Kenya, 2008. Available at http:// www.unep.org/geo/geo4/media/.

(2) Baccini, P. Understanding regional metabolism for a sustainable development of urban systems. Environ. Sci. Pollut. Res. 1996, 3 (2), 108-111.

(3) Engel-yan, J.; Kennedy, C.; Saiz, S.; Pressnail, K. Toward sustainable neighbourhoods: the need to consider infrastructure interactions. Can. J. Civ. Eng. 2005, 32, 45-57.
(4) Junnila, S.; Horvath, A.; Guggemos, A. Life-cycle assessment of office buildings in Europe and the United States. J. Infrastruct. Syst. 2006, 12 (1), 10-17.

(5) Worth, Z.; Boyle, C. A.; McDowall, R. L. Combined life cycle cost assessment of roofing construction. Proc. ICE Eng. Sustainability 2007, 160 (4), 189-198.

(6) Sahely, H.; Kennedy, C.; Adams, B. Developing sustainability criteria for urban infrastructure systems. Can. J. Civ. Eng. 2005, 32, 72-85. Horvath, A.; Matthews, H. S. Sustainability of transportation and other infrastructure systems. J. Infrastruct. Syst. 2005, 11, 1.

(7) Grimm, N.; Faeth, S. H.; Golubiewski, N. E.; Redman, C. L.; Wu, J.; Bai, X.; Briggs, J. M. Global change and the ecology of cities. Science 2008, 319, 756-760.

(8) World Commission on Environment and Development. Our Common Future; Oxford University Press: Oxford, U.K., 1987.

(9) Carpenter, S. R.; Walker, B.; Anderies, J. M.; Abel, N. From metaphor to measurement: Resilience of what to what? Ecosystems 2001, 4, 765-781.

(10) Folke, C.; Carpenter, S.; Elmqvist, T.; Gunderson, L.; Holling, C. S.; Walker, B. Resilience and sustainable development: Building adaptive capacity in a world of transformations. Ambio 2003, 31 (5), 437-440.

(11) Fiksel, J. Sustainability and resilience: Towards a systems approach. Sustainability: Sci., Pract. Policy 2006, 2 (2), 14-21.

(12) Zimmerman, J. B.; Mihelcic, J. R.; Smith, J. A. Global stressors on water quality and quantity: sustainability, technology selection, and governance in a dynamic world. Environ. Sci. Technol. 2008, 42 (4), 4247-4254.

(13) Holling, C. S. Understanding the complexity of economic, ecological and social systems. Ecosystems 2001, 4, 390-405.

(14) Gotts, N. M. Resilience, panarchy, and world-systems analysis. Ecol. Soc. 2007, 12(1), 24. http://www.ecologyandsociety.org/ vol12/iss1/art24/.

(15) Allenby, B.; Fink, J. Toward inherently secure and resilient societies. Science 2005, 309, 1034-1036.

(16) Brand, F. S.; Jax, K. Focusing the meaning(s) of resilience: resilience as a descriptive concept and a boundary object. Ecol. Soc. 2007, 12(1), 23. http://www.ecologyandsociety.org/vol12/ iss $1 / \operatorname{art} 23 /$.

(17) Office of Climate Change The Stern Review on The Economics of Climate Change. HM Treasury, London, U.K., 2006. http:// www.hmtreasury.gov.uk/sternreview_index.htm.

(18) IPCC IPCC Fourth Assessment Report: Climate Change 2007 World Meteorological Organization, Geneva, Switzerland. http:// www.ipcc.ch/publications_and_data/publications_and_data reports.htm.

(19) United Nations. World Urbanisation Prospect: 2007 Revision. UNESA, Geneva, Switzerland. http://www.un.org/esa/population/ publications/wup2007/2007WUP_ExecSum_web.pdf.

(20) ASCE Report Card for America's Infrastructure 2009 American Society of Civil Engineers, Reston, VA. http://www. infrastructurereportcard.org/.

(21) Tsoskounoglou, M.; Ayerides, G.; Tritopoulou, E. The end of cheap oil: Current status and prospects. Energy Policy 2008, 36, 3797-3806.

(22) Gordon, R B.; Bertram, M.; Graedel, T. E. Metal stocks and sustainability. Proc. Nat. Acad. Sci. U. S. A. 2006, 103 (5), 12091214.

(23) Mudd, G. M. The Sustainability of Mining in Australia: Key Production Trends and Their Environmental Implications for the Future; Department of Civil Engineering, Monash University and Mineral Policy Institute: Melbourne, VIC, October 2007; revised April 2009.

(24) Warren-Rhodes, K.; Koenig, A. Escalating trends in the urban metabolism of Hong Kong: 1971-1997. Ambio 2001, 30 (7), 429438.

(25) Kennedy, C.; Cuddihy, J.; Engel-Yan, J. The changing metabolism of cities. J. Ind. Ecol. 2007, 11 (2), 43-59.

(26) Best Foot Forward City limits: A resource flow and ecological footprint analysis of Greater London. Chartered Institution of Wastes Management, London, U.K., 2008. http://www. citylimitslondon.com/downloads/Complete\%20report.pdf.

(27) Banister, D. Cities, mobility and climate change. J. Ind. Ecol. 2007, 11 (2), 7-10.

(28) Woodcock, J.; Edwards, P.; Tonne, C.; Armstrong, B. G.; Ashiru, O.; Banister, D.; Beevers, S.; Chalabi, Z.; Chowdhury, Z.; Cohen, A.; et al. Public health benefits of strategies to reduce greenhouse-gas emissions: urban land transport. Lancet 2009, 374, 1930-1943.

ES903749D 